\title{
Spatial Orientation, Geomedia and Learning: The design of a Comparative Empirical Study
}

\author{
Matthias GROESSLER ${ }^{1}$, Detlef KANWISCHER ${ }^{2}$ and Engelbert NIEHAUS ${ }^{1}$ \\ ${ }^{1}$ University of Koblenz-Landau/Germany·groessler@uni-landau.de \\ ${ }^{2}$ Goethe-University, Frankfurt a. M./Germany
}

This contribution was double-blind reviewed as extended abstract.

\begin{abstract}
Strongly connected to the change in key media from the "Gutenberg-Galaxy" to the "Internet-Galaxy" is also the hope, to break new ground and more successful ways within competence building in the area of spatial orientation. This paper deals with two questions: Which influence on competence building in the area of spatial orientation does the different identification and collecting possibilities within the work with digital geomedia have compared to the traditional work with paper maps? Furthermore, the study is concerned with the influence of different work instructions for the pupils on the learning environment. By means of an interdisciplinary study combining the two fields of mathematics and geography, these questions will be addressed. The empirical research, which the study is based on, has been conducted with four fifth-grade classes of a comprehension school in buildings of the University of Koblenz-Landau. In this contribution, the subject specific background and the test design of the study will be explained as well as the first results presented. These points to some differences of the competence building process between the work with digital media and the work with paper maps.
\end{abstract}

\section{Introduction}

In the course of human history there has always been a change in key media. We are currently living in a transition period from the "Gutenberg-Galaxy" to the "InternetGalaxy" (for detailed information see GIESECKE 2002, CASTELls 2001, DEBRAY 2003). Baecker (2007) refers to the technological revolutions in media, namely the introduction of scripture and book printing, metaphorically as 'catastrophes': "In each of these disasters exploded the surplus meaning to be handled by society and (...) forms of culture had to be found, which made it possible to either reject this surplus meaning selectively or to accept it positively" (BAECKER 2007, 34; trans. by author). In other words, this means that every media technology revolution leads to, on the one hand, technical questions, on the other, to societal responses to questions about the meaning of each technology which need to be discussed in certain areas of social functioning, such as, for example, the question of the additional value of digital media in education.

For nearly 20 years, the additional value of this 'catastrophe' as well as its consequences and benefits are being discussed in the context of the growing spread of digital Information 
and Communication Technologies (ICT) in education. The social, educational as well as the didactic discussions are highly dispersed. For example, the current OECD initiative "The New Millennium Learners" (NML) has set itself the objective to examine the impact of digital technologies on the learning of children at school and has come to the following conclusion: "Therefore, there is a NML case built on the eventual contradiction and perplexity that students may experience when realizing that digital technologies are so important in their daily lives - as they are so in the world of adults, Particularly at work except when they are in classrooms, where even mobile phones are usually banned. Even worse, they can even see that in important technological infrastructure is in place, but under-used" (OECD 2008, 4). Against this background, fundamental reforms in the education system are considered necessary. The assumption that there exists a generation of "New Millennium Learners" is not uncontroversial. SCHULMEISTER (2009) raises the question "Is there a "net generation"?" and asked, "What is in stake the intention of the OECD?" He answers this at once: "It is about policy responses in order to influence the educational system in the interest of the clientele of the OECD, the economy, reasoned with the fictional ideal of the knowledge society in mind" (SCHULMEISTER 2009, 65; trans. by author). In his meta-analysis, SCHULMEISTER (2009) devotes himself to the question whether the often propagated net generation really exists and which effect this would have on the education system. He concludes: "The most significant criticism which can be made about the writers of the Millennial or the Net Generation is that they plaster the fundamental diversity of youth by using the cliché of the generation; thus, obscuring exactly those learning characteristics which are essential to educators, teachers and professors" (SCHULMEISTER 2009, 152; trans. by author).

As an interim conclusion it can be said that it will come to a change in key media at school, which will be adjusted to the digital world of the students. At the same time, however, one can also notice that the discussion on ICT in education is characterized by an enthusiasm for the possibilities of computers and teaching's only task seems to be to make everyday usage scenarios, such as GPS, Google Earth or other localization services fruitful for teaching. This is certainly desirable, but has little to do with didactic innovation. This would require it to be the other way round. As a first step, problems and needs of the learners and the learning process itself must be defined and not till then resort to possible ICT applications which have an additional value (surplus meaning) with regards to the identified challenges in contrast to traditional. If 'High-Teach' come before 'High-Tech', then it will be made possible for teachers not only to respond to the hardware and software developers and to make their tills ringing, but also actively shape the learning environment of their students with the help of ICT.

These preliminary remarks shall serve as the starting point of our contribution. As part of an interdisciplinary empirical research project, represented in the geography education and mathematics education, we will contribute to the following paramount question: What are the topic areas and learning environments where smartphones can be useful and do they contribute the success of learning in school life? To answer these questions, we conducted an empirical study. The focus of the paper is on the presentation of the study design. Founded upon the questions of the research, we will describe the methodology setup, the teaching setup and the underlying instruments of measurements. Finally, we will depict the implementation of the study and give first insights of the results. 


\section{Didactical Background and Research Questions}

Subject-specific structures of knowledge and the underlying methods of acquiring and consolidating this knowledge are often not limited to one subject alone. Some of these methods can be transferred from one domain to another and onto everyday contexts. This is the case of the field of spatial orientation. Spatial orientation is the ability to orient oneself in space and is one of the main competence areas within the school subject of geography (German GeOgraphical Society 2012, CommitTeE ON GeOGRAPHy 2000). The area of expertise in spatial orientation not only has a high relevance for everyday life, but also serves as a methodological basic qualification for other subjects. Conversely, students need skills taught in other subjects in order to develop spatial orientation skills. For example, mathematic skills are required to work with benchmarks, such as the terrestrial coordinate system. In addition, working with maps that represent a subjectively created spatial model of reality is based on the students' ability to imagine a concept of space; an ability which is a major part of the mathematics education in the area of the competence modeling (Kultusministerkonferenz 2003, NATional Council of TEACHERs OF MATHEMATics 2000).

Research within the field of spatial orientation has traditionally been an interdisciplinary endeavor. Besides geography and mathematics the discipline of psychology is strongly represented in this research area (NATIONAL ACADEMIES 2006). The emergence of new digital media, for example, GPS, digital maps and geographical information systems which has gained a firm hold in the everyday lives of students during the last years, has given rise to the hope of improving the education of spatial orientation within secondary schools. According to an empirical educational research perspective, there is still a lack of scientific research in the area of digital geomedia compared to publication of the application of digital geomedia in the classroom (SCHULZE \& KANWISCHER 2012). However, there is some indication that, comparing between the work with traditional paper maps and digital geomedia, as, for example, working with Global Positioning System (GPS)-based mobile devices, there are differences in the effectiveness of way finding (ISHIKAWA et al. 2008) and that GIS learning helps students think spatially (LEE \& BEDNARZ 2009). Our research project will contribute to the discussion on whether there is an improved learning success in the field of spatial orientation when teaching uses digital geomedia compared to traditional analog geomedia.

The well-known IMAP model (input, management, analysis, presentation) serves as a starting point for our research questions. The model describes expertise for handling geographical information. The identification and collection of spatial information stands at the beginning of the cognitive process. Against this background we decided to put the research focus on this topic. Additionally, while there are currently no specific empirical insights into how the process of identification and detection of spatial data can be taught, we investigated also the question about the influence of varying degrees of work instructions on the learning process. Our research questions are:

- What influence does the different identification and collection possibilities of spatial information in the work with digital geomedia compared to the traditional work with paper maps of competence building in the area of spatial orientation have? 
- What influence does the different work instructions for the pupils for the identification and collection of spatial information have?

\section{$3 \quad$ Target Group and Study Design}

As a group of subjects, we decided on ten- and eleven-year old students, since this age group attends the fifth grade in the German school system, in which the identification and collection of spatial data is for the first times taught as part of the curricular subject area "spatial orientation" within in the subject of geography. At the beginning of the school year, the curriculum for the fifth grade includes the topic "ability to use maps for orientation".

The study was conducted with 115 pupils of the fifth grade of a comprehensive school in Landau. The classes were divided into different groups of about ten to fifteen pupils. In the study design the pupils were divided into six groups, which differ, first of all, in the usage of digital maps via smartphones and paper maps. The second distinction relates to the provision of work instructions for the recording of the exercises. Two groups had workbooks with elaborate work instructions. One of those two groups worked with mobile devices, the other one with maps. Two other groups had to record their exercises and results into workbooks with very short work instructions. The remaining two groups had work instructions, which decreasing staggered instructions during the four units (see table 1).

Table 1: Teaching unit design of the empiric study

\begin{tabular}{|c|c|c|c|c|}
\hline \multicolumn{1}{|c|}{} & \multicolumn{4}{c|}{ Work Instructions } \\
\cline { 2 - 5 } & & Elaborated & Staggered & Short \\
\cline { 2 - 5 } $\begin{array}{c}\text { Smart- } \\
\text { Phone }\end{array}$ & Yes & Group 1 & Group 3 & Group 5 \\
\cline { 2 - 5 } & No & Group 2 & Group 4 & Group 6 \\
\hline
\end{tabular}

Independent from the study design, all of the groups were supposed to cover the same topic and subtopics in four teaching units over 90 minutes and, at the end of each unit, the learning results were reflected in the groups. In the first unit, the focus was on spatial orientation with landmarks. The pupils learned how to become familiar with the topology of the near surroundings. Therefore, they created "subjective maps" of their personal description of their way to school. "Subjective maps" were again used in the second unit to teach the pupils that the perception of space is always selective and subjective. Furthermore, they learned that representations of the space are always simplified and constructed. A subtopic of this unit was the creation of written directions with the help of landmarks. The main topic of unit three was the analysis of tracks. In the first part of the unit the pupils learned how a track is created by exploring the campus with smartphone or paper maps. They had to transfer their findings, first, into iconic sketches and later into their own descriptions of the track. With this knowledge, the pupils tried to analyse different tracks and understand the different reasons and dependability for different tracking-point distances. The last unit of the study focused on the analysis of spatial 
situations and fair distribution of resources. First of all, the pupils learned how to describe spatial relations of objects. Later they solved spatial resource allocation problems and tried to determine locations for common used resources regarding several requirements and constraints.

\section{Test Design}

The selected test-design is a pre-, post-, follow-up-test-design. The pre-test was conducted directly before the first unit and the post-test after the last one. Additionally, a follow-uptest was conducted twelve weeks after the post-test to analyze long-term effects. The test of the empiric study contained items to analyze competences of spatial orientations, reproduction via recording the learned contents and transforming content between the different kinds of representation. At the beginning it had a short general introduction in which the pupils get explained why he or she did the test and which topics were addressed in the test. The introduction was followed by personal questions of the pupils and questions regarding the pre-knowledge about mobile devices and the use of topological maps. The next items questioned the competence of spatial orientation and creation of directions, followed by items questioning track analysis and assessment of spatial situations. The test was closed by logic exercises.

\section{Outlook}

The empirical study was conducted successfully. The assessment of the test results and the workbooks is still in progress. Based on the practical experience with the work with the pupils, some aspects can be identified which probably have an influence on the differences in the learning of competences between working with digital geomedia and the traditional work with paper maps. One important aspect is the data collection with mobile devices that offers the user the possibility to add photos, etc. to the landmarks when recording them, thus, adding more information to the maps than just notes to topographic maps. Consequently, it seems as if the selection of motifs while taking photos and saving landmarks creates additional understanding of landmarks, thus improving the spatial orientation of the pupils. Regarding the different levels of work instructions, there have no definite results been established as yet since the heterogeneity of the groups has to be taken into account and the analysis has not been completed.

The test design and the selection of the topic of the study and the exercises in combination with the age of the pupils have worked successfully. In this study the pupils were divided into groups randomly before the pre-test. In order to optimize the test design, one would create more homogenous groups in the future by dividing the groups into high-achievers and low-achievers, according to the pre-test assessment, or by putting an equal number of both kinds within one group. Another crucial point is the extent of the tests. For further studies one has ensure that the amount of exercises per test fits to the heterogeneity of the pupils so that the low-achievers will also be able to solve the exercises and still cover all the necessary subjects to answer the research questions. Furthermore, one should reduce the introduction texts per exercise to enable the low-achievers to solve them. Otherwise it is 
difficult to decide whether the pupils are not able to do the exercises because of intellectual reasons or time capacity reasons. The more elaborate discussion of these first insights and the analysis and interpretation of the empirical data will be presented in future publications.

\section{References}

BAECKER, D. (2007), Studien zur nächsten Gesellschaft. Frankfurt a. M.

Castells, M. (2001), The Internet Galaxy. Reflections on Internet, Business and Society. Oxford.

Committee on Geography, National ACADEmies Commission on Geosciences, ENVIRONMENT, AND RESOURCES (2000), Support for Thinking Spatially: The Incorporation of Geographic Information Science Across the K-12 Curriculum. Unpublished manuscript. Washington D.C.

DEBRAY, R. (2003), Einführung in die Mediologie. Facetten der Medienkultur. Bern.

GERMAn GeOGRAPHICAL SocIETY (Eds.) (2012), Educational Standards in Geography for the Intermediate School Certificate with sample assignments. Second edition. Bonn.

GIESECKE, M. (2002), Von den Mythen der Buchkultur zu den Visionen der Informationsgesellschaft. Frankfurt a. M.

ISHIKAWA, T., FUJIWARA, H., IMAI, O. \& OKABE, A. (2008), Wayfinding with a GPS-Based mobile navigation system: A comparison with maps and direct expirience. Journal of Environmental Psychology, 28 (1), 74-82.

KultUSMINISTERKONFERENZ (KMK) (Eds.) (2003), Bildungsstandards im Fach Mathematik für den mittleren Schulabschluss. Bonn.

LEE, J. \& BEDNARZ, R. (2009), Effect of GIS learning on Spatial Thinking. Journal of Geography in Higher Education, 33 (2), 183-198.

NATIONAL ACADEMIES (2006), Learning to think spatially. Washington, DC.

OECD (Eds.) (2008), New Millennium Learners. Initial findings on the effects of digital technologies on school-age learners. OECD/CERI International Conference "Learning in the 21st Century: Research, Innovation and Policy”. Paris.

SCHULMEISTER, R. (2009), Gibt es eine „Net Generation“? Hamburg.

SCHULZE, U. \& KANWISCHER, D. (2012), Empirical GIS Education Research - Review of Contributions to the GI_Forum. In: Jekel, T., CAR, A., Strobl, J. \& Griesebner, G. (Eds.), GI_Forum 2012: Geovisualisation, Society and Learning. Berlin/Offenbach, 261-271. 